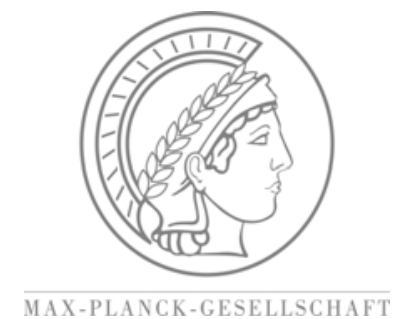

\# 1009

On the Evolution of Organizational Government

by

Roger D. Congleton

The Papers on Economics and Evolution are edited by the Evolutionary Economics Group, MPI Jena. For editorial correspondence, please contact: evopapers@econ.mpg.de

Max Planck Institute of Economics Evolutionary Economics Group Kahlaische Str. 10 07745 Jena, Germany Fax: ++49-3641-686868

ISSN 1430-4716

(C) by the author 


\title{
On the Evolution of Organizational Government ${ }^{1}$
}

Roger D. Congleton

George Mason University

7-28-10

Max Planck Institute Working Paper (EVO)

\begin{abstract}
This paper analyzes the design, refinement, and evolution of organizational policymaking processes, that is to say, organizational governance. Governance procedures like other aspects of organization are refined through time to advance formeteur interests. Several mechanisms of evolution are explored in this paper. First, formal organizations have a beginning. They are founded. As a consequence, governance templates initially tend to maximize formeteur control over their organizations. Second, formeteurs may subsequently revise the initial distribution of authority. There are often good reasons for formeteurs to exchange some of their initial authority for services and resources that advance organizational interests. Third, there are the constraints of survivorship, which require an organization to attract sufficient resources to be self sustaining. This paper suggests that the results of these processes of refinement tend to be ruledriven, divided governments, many of which will be based on the king and council template. That template facilitates the emergence of relatively effective forms of organizational governance, because it can be adjusted at a large number of margins without changing the essential architecture of governance.
\end{abstract}

\section{Introduction}

Formal organizations are an invention, like the wheel and wedge, that are not found in nature. Like those other inventions, formal organizations have played many important roles in human history. And in a manner similar to the wheel and wedge, specific implementations of organizations have been refined through time as new problems have been confronted, new methods of production imagined, and successive generations of organizers learned from previous ones. Indeed, much of what separates humanity from the animal kingdom can be attributed to organizations that intentionally coordinate human activities to create more than would be possible for the same individuals operating independently of one another alone or in spontaneous groups.

\footnotetext{
${ }^{1}$ This paper was written while a visiting fellow at the Max Planck Institute for Evolutionary Economics, whose support is gratefully acknowledged. The present version of the paper benefited from several helpful comments from Ulrich Witt and conversations with several of the institute faculty, while at the institute.
} 
How such organizations are formed tends to be neglected by economists and political scientists in order to focus on the properties of particular reward and recruitment systems or to analyze equilibrium properties of spontaneous orders, such as markets and political culture. How and why organizations improve through time has been neglected for similar reasons. Most mainstream work tends to be "middle run," insofar as it assumes that the pool of existing organizations and services are "given," rather than subjects of analysis.

Unfortunately, by neglecting the founding and refinement of organizational designs, the resulting theories of economic and political organizations miss much that is important about the nature of existing organizations and about how organizations change through time. Both the founders and subsequent leaders of organizations are continuously engaged in efforts to improve the performance of their organizations and often do so by revising their organizations' standing routines. If policymaking is the main task of an organization's government, it can be argued that the "governance" literature in economics addresses only a subset of those policies, namely those affecting reward and recruiting systems. (See, for example, Williamson's extensive work in this area.)

It is the design, refinement, and evolution of organizational decisionmaking procedures that is the main focus of the present paper. This paper begins by focusing on the origins of formal organizations. That formal organizations are intentionally founded has a number of implications that are important for the analysis. Organizations are normally founded by a small subset of their members. The person or persons that found organizations are called "formeteurs" in this paper and the other persons in their organizations are called "team members." That organizations are founded by formeteurs, rather than team members, implies that organizations are designed to advance the purposes of formeteurs, rather than their members.

One consequence of this is that decisionmaking authority within an organization tends to be initially distributed in a manner that maximizes formeteur control over their organization. In most cases, however, divided forms of governance tend to replace the initially authoritarian ones as market-like shifts of authority take place. For example, as developed below, it is often in a formeteur's interest to trade and/or delegate some of his/her initial authority to others in exchange for services and resources that advance his 
her organizational interests. Contemporary private firms often raise capital by selling off voting rights, and medieval kings often traded parliamentary authority for new taxes.

This paper suggests that such divided governments are often based on the "king and council" template, because that template solves a variety of common governance problems.

The king and council template divides policymaking authority between a king (a chief executive officer, chief, king, president, etc.) with a council (board of directors, council of wise men, cabinet, parliament, etc.). Several of the reasons why the king and council template tends to be widely used are discussed in the middle sections of this paper. Among the most important for the purposes of this paper is that the king and council template can be easily adjusted through time, which allows it to be subjected to incremental experiments, refinement, and improvement. Its many margins of adjustment allow it to be perfected gradually as a template for government in the long run. These same margins also allow it to serve as a very useful analytical framework for studying the evolution of organizational government. ${ }^{2}$

The king and council template for organizational governance is extremely common. It is used by armies (commanding general and council of war), by religious organizations (pope and council of cardinals), by modern corporations (chief executive officer and board of directors), by primitive governments (chief and council of wise men) and by contemporary democratic governments (president or prime minister, and parliament).

The arguments and models developed in this paper are extensions of work developed in part 1 of Perfecting Parliament (Congleton 2011). This paper differs from the book in that it focuses on the evolutionary possibilities of organizational governments in general, rather than specific features of territorial governance and external shocks that allowed liberal democracy to emerge in the nineteenth century. Several of the arguments presented briefly in this paper, however, are developed at greater length in the book, especially those dealing with territorial governance.

\footnotetext{
${ }^{2}$ Nelson and Winter (1982) launched the modern research program on evolutionary economics. See Witt (2006) for a nice overview of research and research issues in the work that followed their pioneering effort. Wohlgemuth (2002) provides a careful survey of issues and contributions to evolutionary theories of politics. However, the organizational governance (constitutional) issues focused on in this paper are not mentioned in such surveys. There are, for example, no discussions of the extent to
} 


\section{The Origins and Evolution of Organizations}

In the days before histories were recorded, few distinctions existed between governments and other informal organizations. Both were evidently family and clan based. As agriculture emerged and people settled in particular places, the variety and size of organizations and governments tended to increase. There were simply more activities that could benefit from organized team production. That more activities took place within formal organizations and within territories ruled by governments did not imply that all activities were organized from the top down, as in totalitarian states. Nor, did it imply that they were all organized in the same way. There are a variety of ways that organizations can be founded-by one, two, or many formeteurs - and many of the same activities may be undertaken by organizations with different decisionmaking procedures.

As organized groups grew larger and more specialized, distinctions began to emerge between organizations that could impose rules only on their own members and those that could impose rules on persons outside their organizations during this time. This distinction between organizations did not imply that the internal decisionmaking procedures used by territorial governments were completely different from those used in other organizations. It simply meant that some organizations had opportunities that others did not.

With such distant beginnings in mind, the paper analyzes the emergence and evolution of formal organizations. The analysis helps explain how and why ancient organizations provide the foundations for contemporary ones, although very few contemporary organizations are thousands of years old. The connection between ancient and contemporary organizations is not through the continuity of the organizations themselves, but rather, a consequence of the similarity of the problems faced by ancient and contemporary organizations. It is the solutions to these problems that induce groups of persons to become "organizations," rather than simply gatherings of uncoordinated persons, each doing their own thing.

Both ancient and contemporary organizations are formed to advance goals that can best be achieved by coordinating the efforts of more than one person. The outputs of

which a general evolutionary theory of organizational governance can be developed or applied to both private and political organizations. 
organizations normally take the form of (a) private goods produced with economies of scale over some range of inputs, (b) pure public goods available to all team members, or (c) services that can be more effectively distributed to others outside the organization through organized efforts.

Both ancient and modern organizations have to make decisions that focus their resources on particular activities and induce their team members to function as more or less productive teams, rather than as unproductive assemblies of individual shirkers and rent seekers. As a consequence, most organizations meet at particular times and places. Most use artificial incentive systems to address various team production problems. Most have particular persons whose decisions can focus the organization's resources on particular tasks and change the manner in which those resources are used. The "leadership" of hunting clubs, farm cooperatives, churches, pirate ships, commercial enterprises, and territorial governments all select projects to undertake and provide internal incentives for undertaking them.

Relatively durable organizations are also able to revise their objectives, reward systems, and procedures for making decisions as circumstances change. In this manner, a durable organization's government may be said to evolve. And, insofar as the practices of organizations become known to others, one organization's evolution may affect the standing routines of other existing organizations and others yet to be founded.

\section{On the Requirements and Convergence of Reward Systems}

To understand some of the policy decisions made by a typical organizational government and the constraints under which an organization's leadership operates, it is useful to analyze the formation of a new organization. The first case analyzed can be thought of as that of the "first" formeteur, although it can be used to analyze a variety of problems that contemporary formeteurs have to overcome to create a viable organization. Section III focuses on the choice of reward and recruiting systems, which indirectly sheds a good deal of light on the nature of institutional design and rule making by organizational governments. Sections IV and V analyze the third core problem-that of governance. 


\section{A. The Essential Economics of Rewards and Punishments}

Table 1 presents two game matrices. The game on the right is assumed to be a preexisting or natural game and the one on the right an artificial game contrived by a formeteur. The game on the left characterizes production in a "natural cooperative," in which team members participate in a common venture (perhaps a hunt or harvest) and share the output produced. It is sensible for a player to participate in the cooperative's activities, if he or she is better off in the cooperative than in alternative activities (exit), such as independent production by themselves (or in another cooperative).

Note that the upper four cells of the left-hand game characterize a prisoner's dilemma (PD) game and represent rewards from participating in the cooperative's team production. These payoffs imply that team members choose to participate in the cooperative activities, rather than exit, but do not work as hard as required to maximize the cooperative's output. In this sense, they "shirk," rather than "work." Nonetheless, the natural cooperative is viable, because, in equilibrium, each participant receives more than he or she would obtain by working alone $(2>1.5)$.

\section{Table 1}

\section{The Shirking Dilemma}

Game for Natural Cooperatives

\section{Organizational Solution to the Shirking Dilemma}

\begin{tabular}{llll} 
& \multicolumn{3}{c}{ Team Member B } \\
& Work & Shirk & Exit (B) \\
Work (A) & 3,3 & 1,4 & $1.5,1.5$ \\
Shirk (A) & 4,1 & 2,2 & $1.5,1.5$ \\
Exit (A) & $1.5,1,5$ & $1.5,1.5$ & $1.5,1.5$
\end{tabular}

Team Member B

Work Shirk Exit (B)

Work (A) R, R R, P 1.5, 1.5

Shirk (A) P, R P, P 1.5, 1.5

Exit (A) $\quad 1.5,1.5 \quad 1.5,1.5 \quad 1.5,1.5$

The cell entries are utilities, the rank order of subjective payoffs for the team members (A, B).

The fact that output is not maximized by the natural cooperative provides an opportunity for a "formeteur" (or group of formeteurs) to create a more formal organization with a more sophisticated reward structure. Such formeteurs may be members of the natural cooperative or outsiders that imagine both the possibility of greater production and a reward system to encourage greater effort by team members. 
Team members in the "Organizational Game" on the right have the same strategy sets as in the natural cooperative (work, shirk, exit), but they confront a reward system that is designed to encourage "work." The subjective reward for work is $R$ and the payoff associated with shirking is $P$. The members of the formal organization will work to advance the organizational goals (here, maximize output) if $R>P$. This is made more likely, by disconnecting rewards from joint output. The reward in this game is conditioned only on individual effort, rather than on the performance of the organization as a whole.

Exit options further constrain the values of $R$ and $P$ that formeteurs can choose. Individuals will, for example, join the new team only if $R$ is greater than 2 , so that they are better off than at the natural cooperative. Punishment payoff $P$ may also affect decisions to join or not. If punishments are imposed in an arbitrary or inaccurate manner, potential team members may fear that they may occasionally receive $P<2$ even if they are working hard. They will be more likely to join and less likely to exit if they believe (expect) that only "shirkers" will be punished. Thus, $R>2$ is sufficient to discourage exit only if the average level of rewards, including mistaken punishments, is greater at the new organization than at the natural cooperative (adjusted for risk).

\section{B. Choosing Specific Reward Systems}

The theory of organizational design sketched out above and used below rests on two assumptions. The first is that an organization's formeteurs are able to create gamelike settings in which they determine the (subjective) payoffs for team members. In the illustration above, they did so by creating conditional rewards for working and shirking. The second assumption is that formeteurs design their organizations with their own organizational objectives in mind, although they do not have sufficient knowledge to design the best possible organization.

Of course, these two assumptions can be further subdivided into others. For example, the assumption that a formeteur can create a game in which team members feel constrained to play by the rules essentially assumes that formeteurs can solve their reward and recruitment dilemmas. The specific methods required to do so will vary somewhat with the external setting, as developed below. This paper abstracts from associated issues_-such as conditional propensities to cooperate in structured settings or to defer to 
organizational leaders - in order to focus on general features of the reward systems that emerge that have relevance for organizational governance. ${ }^{3}$

It is often convenient to assume that formeteurs attempt to maximize organizational surplus. Organizational surplus can be thought of as profit or net resource flow to the organization. Such net flows can be used for a variety of purposes by formeteurs. Organizational surplus may be used to provide capital for the organization or to provide a buffer for unexpected negative shocks. It can be used to found other organizations, which may not be initially self-supporting. It can also be used to enhance the formeteur's personal consumption or even given away to charity. The surplus itself may be realized in pecuniary terms (money or physical resources), subjectively appealing nonpecuniary ones (status, deference, or creative satisfaction), or various combinations of each.

If formeteurs attempt to maximize organizational surplus, they will be inclined to adopt the least expensive reward systems that solves their team production problems. In many cases, several combinations of pecuniary and nonpecuniary rewards may elicit the behavior of interest. It bears noting that rewards in most organizations include status, praise, and prizes in addition to pecuniary rewards (salaries). Here, one may note the use of special badges and uniforms in military organizations to encourage extreme effort, sacrifice, and bravery. Similar nonpecuniary "perks" are also used to motivate team members of modern corporations and government officials, for whom the relative size of offices, company cars, parking place locations, and titles are used to indicate position in the intraorganizational status hierarchy. It is also clear that punishments for shirking can also be multidimensional.

\footnotetext{
${ }^{3}$ The assumption that formeteurs can affect subjective payoffs, $R=u\left(R^{o}\right)$ and $P=u\left(P^{o}\right)$, is equivalent to assuming that formeteurs can raise and lower objective payoffs $R^{\circ}$ and $P^{o}$ for their team members.

In some settings, the formeteur may do so by directly producing resources that can be used to affect $R^{o}$ and $P^{o}$, as when praise and criticism can affect their team members' subjective welfare. In other cases, the formeteur may simply use the team's output as a source of rewards and punishments. In such cases, the formeteur's control over the team's output may be itself a product of organization and team production. There may be specialized monitor-enforcer teams and/or the team's output may be placed in a safe place controlled by the formeteur(s). Formeteur control of team output may also be supported by widely accepted norms of deference to leaders or by other external sanctions. For example, the organization may take place in a setting where civil law exists.

It bears noting that I do not make the Hobbesian assumption about anarchy, as many do in this literature, which essentially rules out the formation of small teams in which organizational surplus can exist, absent leviathan. Rather, I assume that there are places where at least a few persons can escape from "the war of every man against every other." Here, it bears noting that many animals have genetic predispositions to respect each other's territory, rather than contest it at every moment.
} 


\section{Culture and the Cost of Reward Systems}

Opportunities to use nonpecuniary rewards to address team production problems are partly culture dependent. For example, the local culture may include support for bravery, a work ethic, honesty, or rule-following behavior. Vanberg and Congleton (1992) suggest that propensities to cooperate (conditionally) have survivorship value in environments where exit is possible, and thus norms that help to induce cooperation tend to emerge in most societies. In such cases, formeteurs can economize on monitoring costs and encourage rule-following behavior by reminding team members of the merits of local norms and rewarding norm-driven behavior. Awards might be given to persons who never miss a day of work, are especially diligent, or are especially loyal to the organization.

Formeteurs may also attempt to create stronger versions of local norms or their own norms, an "organizational culture," by encouraging hard work, loyalty, and useful innovation in various ways. When an organizational culture is successful, it may indirectly affect the local external culture. Team members may take their organizational norms home with them, apply them to other parts of life and teach them to their children. Efforts to recruit persons that have already internalized the organization's norms also encourages unaffiliated persons in the community to adopt those norms.

Composite reward systems make sense whenever they can solve the incentive problems of team production at a lower cost than an entirely pecuniary system of rewards and punishments. Instances of composite systems of such rewards are most obvious in military and religious organizations, but also occur in governments, private clubs, and contemporary corporations. Indeed, the latter often copy ideas from military and religious organizations and have their own rituals and medals of honor.

The problem of motivating team members can also be reduced through various recruiting methods. Some people have goals, world views, and norms that are more "naturally" aligned with the goals of a particular organization. Such persons are especially valuable for organizations, when they are available, and will be recruited while others whose norms are counterproductive will be discouraged from membership. For example, formeteurs may attempt to attract members who are easy to motivate or demonstrate that they have "internalized" useful norms, such as rule-following behavior or a work ethic. 
For example, in table 1 the punishment may be purposely set at $\mathrm{P}<2$, so that persons who are difficult to motivate (natural "shirkers") remain at the natural cooperative, instead of joining the new organization. Churches thus recruit believers, rather than atheists, for their organizational bureaucracies. Military organizations similarly recruit those who accept the necessity of violence, rather than pacifists. Governments normally recruit persons who signal loyalty to their organizations, rather than dissidents or persons from abroad. Commercial firms are inclined to hire those who indicate their interest in high incomes or being "team players," rather than stubborn idealists or individualists, unless the latter clearly have interests that are well aligned with the organization's objectives. Other directly productive skills also matter, as emphasized by educators and economists, but they are not necessarily the most important type of human capital for determining a person's productivity on a given team.

\section{Exit as a Constraint on Organizational Reward Systems}

As noted above, there are limits to a formeteur's ability to manufacture a cooperative culture, and limits to the extent to which intrinsic motivation can be used to solve team production problems. There is also competition among formeteurs for tractable team members, which tends to increase exit options for such persons. Such constraints limit the extent to which surplus can be extracted by formeteurs. Although the reward systems chosen by formeteurs will attempt to minimize the compensation paid to team members, the reward-penalty system must be sufficient to attract and retain team members and solve the team production problems.

In the illustration above, the formeteur might pay team members $R=2.1$ for work and $P=1.6$ if they are found to be shirking. The team production equilibrium in this case is (work, work) and the organization's total output is 6 . The total cost of the reward system will be $2 \times 2.1=4.4$ and the organizational surplus is $6-4.2=1.8$ (less a small amount for accurate monitoring of work effort). If team-member exit options improve from 2 to 2.5 , a reward such as $\mathrm{R}=2.6$, becomes necessary and organizational surplus falls to $6-5.2=0.8$.

In the absence of exit options, severe punishments might be used to encourage "cooperation." For example, given an $\mathrm{R}$ sufficient for the survival of a team member, any $\mathrm{P}$ $<\mathrm{R}$ below that will induce cooperation if there are not exit options. Evidently, the sys- 
tems used to motivate slaves were often centered on punishments, rather than rewards. The exit options of slave were often very limited, because they were limited by law as well as by their masters. If imposing such punishments is less costly than providing workinducing rewards, formateurs will be inclined to use penalties, rather than rewards to encourage productive effort.

Note also that the cost of a reward-and-punishment system is also affected by arbitrariness and/or error rates. The greater the error rate or arbitrariness of the punishments, the higher average rewards must be to attract and retain team members. The rules for rewarding and punishing team members for working and shirking should be (relatively) stable through time, because this reduces uncertainty among team members and thereby the total compensation required to attract and retain team members. ${ }^{4}$

In general, formeteurs maximize their organizational surplus by choosing the least expensive composite reward system that solves both their team production and recruitment problems. Perhaps surprisingly, minimizing the cost of effective reward systems implies that formeteurs will rely on and may reinforce social norms and that they will not create or enforce rules arbitrarily. Both formeteur and team member interests are advanced by organizations with stable, predictable systems of reward and punishment.

Insofar as evolution favors organizations with relatively larger organizational surpluses, evolution can also be said to favor organizations with their own internal rule of law.

\section{E. The Evolution, Convergence, and Stability of Conditional Reward Systems}

The first formeteurs have to imagine their entire reward systems, which consequently are likely to be very simple ones based on physical "carrots," "sticks," family loyalty, and deference to authority figures. The next formeteur(s) will be able to observe the successes and failures of the first, and copy practices that work and revise (slightly) those that did not. Not all reward systems will work equally well at solving team production problems or advancing formeteur interests.

Subsequent generations of formeteurs will focus their attention on reward and recruiting systems used by more or less successful organizations from previous generations.

\footnotetext{
${ }^{4}$ If $N^{e}=f^{*} u\left(R^{o}\right)+(1-f) u\left(P^{o}\right)$ is the expected net reward, where $f$ is the probability of being wrongfully punished, and $R^{o}$ and $P^{o}$ are objective rewards with subjective values $R=u\left(R^{o}\right)$ and $P=u\left(P^{o}\right)$ re-
} 
As time passes, the systems adopted reflect the experience and experiments of more and more formeteurs, whose organizations would have advanced a variety of goals in a variety of circumstances. As a consequence, the reward and recruiting systems used tend to become more effective through time, in the sense that they increase organizational surplus. The latter is often a consequence of the use of larger teams, which become more productive as reward and recruitment systems improve. Such long-term improvements reflect the insights and experience of many generations of formeteurs, about whom most of the current generation of formeteurs (and other organizational leaders) are likely to be entirely ignorant.

The common problems and interests of formeteurs imply that very similar solutions to intra-firm incentive and governance problems tend to be widely used in culturally and commercially linked regions and applied for long periods. By using a preexisting template for their reward and recruiting systems, formeteurs can economize on their own analysis of reward and recruiting systems and reduce the risk that their organizations will fail to solve specific team production problems in a cost-effective manner. The use of proven "off the shelf" reward and recruiting systems also allows formeteurs to form new organizations more rapidly and to focus more of their attention on other issues that affect the viability of their organization.

The use of such "templates" has several implications of interest for the purposes of this paper. When formeteurs adopt templates from other organizations, they are implicitly acknowledging their limits as organizational designers and also the partly unknown or "spontaneous" nature of their productive internal organizational cultures. Once formeteurs acknowledge their limitations as institutional designers, they have additional reasons to be conservative in their selection of reward systems and their subsequent experiments to improve them.

The unanalyzed and unknown aspects of their reward and recruiting systems imply that there are risks to experimenting with the templates adopted. The various components of reward systems may not be entirely independent of one another; consequently, adjusting even one parameter in a plausible manner may produce unexpected results. The

spectively, then $f=0$ allows total rewards to be smaller than $f>0$, whenever function $u$ is strictly concave and monotone increasing in $R^{o}$ and $P^{o}$. 
evidence surveyed by Frey and Jegen (2001), for example, suggests that increases in explicitly conditional forms of motivation tend to reduce (crowd out) self-motivation and so, surprisingly, may reduce productivity, rather than increase it. In this manner, "rational institutional conservatism" tends to increase both the convergence of reward and recruiting systems and their stability.

The similarity and stability of reward systems in a given time and place do not imply that every formeteur regards his or her organizational form to be the best that can be imagined or that formeteurs are extremely risk averse. Nor does convergence imply that the results are necessarily socially optimal in some sense. For example, excessive conservatism may be induced by a PD-like social dilemma that increases the stability of prevailing practices beyond optimal levels. Individual formeteurs may not be able independently to adopt practices that are more "efficient" without losing team members or customers to their more conventional rivals, even though all formeteurs and team members would be better off with revised practices.

With or without such social dilemmas, however, it remains the case that formeteurs adopt the most cost-effective reward systems that are known and feasible for them and that considerable convergence among reward systems and production methods tends to take place. Pear-harvesting coops will use similar ladders and baskets and use similar combinations of status, fruit, and wages to encourage pears to be picked. Fishing clubs will use similar nets to catch similar fish in similar places and reward their fishermen in a similar manner.

Stable, widely used systems of rewards imply that the anticipated cost of significant reforms exceeds their benefits for formeteurs, given prevailing practices and norms in the communities in which their organizations operate. This is not to say that experimentation stops taking place, but that improvements become increasingly unlikely. Here, one may note that the basic technologies and organizational strategies for produce sellers and churches often appear to be stable for hundreds of years at a time.

When new technologies are occasionally discovered, however, a variety of beliefs (subjective probabilities) about potential opportunities for improving existing methods of team production and organization are often affected. New technologies often "imply" that a variety of technological and organizational experiments are likely to increase organizational surplus. Some of these hypotheses will prove correct, and successful experi- 
ments will be copied by other organizations and applied in new ones. In this manner, advances in organizational design tend to be pushed along by innovations in other technologies, as well as by innovations in reward and recruitment systems that concentrate additional organizational surplus in the hands of formeteurs.

\section{F. A Digression on the Nature of Formeteurs}

The persons that found a formal organization have been called "formeteurs" in this paper, rather than entrepreneurs or founders, for several reasons. Formeteurs have many of the same characteristics emphasized by the foundational texts on economic entrepreneurship. In Schumpeter's (1934) and Kirzner's (1978) terms, a formeteur has, creates, or recognizes organizational opportunities that others do not have or cannot see. Consequently, "innovation," "foresight," "creativity," and "boldness" are often associated with organizational leadership along with exceptional ability to recruit and motivate a team. Formeteurs may also be said to be less risk averse than others (Knight 1921), in that they are more willing to accept the risks associated with launching new enterprises. Formeteurs, however, differ from the entrepreneurs of classic economic analysis, because they form organizations, rather than engage in price arbitrage or create new products. Moreover, the organizations founded may advance noncommercial purposes, rather than or in addition to commercial ones.

Formeteurs also share a number of characteristics with "founders," in that they are present at the founding of their organizations. However, not all founders are actively involved in forming new organizations. They may simply be present at the beginning, rather than actively engaged in designing the organization. Many founders may thus lack leadership skills or entrepreneurial talents.

That a formeteur has to solve a variety of team-production problems also has implications about the nature of the persons who tend to be formeteurs. Formeteurs cannot be "loners." They tend to have unusual motivational skills and organizational insight. Leadership skills often include a relatively large informational base and the ability to persuade others that it is in their interest to defer to the formeteur's direction. Formeteurs also tend to be relatively charismatic people who can induce persons to follow their direction at relatively low cost. Such talents allow formeteurs to influence both technological and cultural developments within their organizations, although they cannot fully control 
them. Their influence over team members, however, is sufficient to allow them to use relatively inexpensive motivational systems, as, for example, various nonpecuniary rewards are substituted for relatively more expensive (or less effective) pecuniary rewards. ${ }^{5}$

Formeteurs are not omniscient, nor are they necessarily geniuses in the usual sense of the word, although they tend to have an unusual ability to see organizational opportunities and to motivate people. Many, perhaps most, new organizations fail, which implies that formeteur insight and abilities to solve organizational problems tend to be quite imperfect. Formeteurs simply have a comparative advantage at forming new organizations. They can start new organizations at a relatively lower cost than non-formeteurs.

\section{Organizational Governance and the King and Council Template}

Having established a number of properties of organizational reward and recruiting systems, we now turn to the problem of organizational decisionmaking. It bears noting that organizational decisionmaking in all but the smallest organizations is normally undertaken by specialized teams, so many of the conclusions reached about reward and recruiting systems for "ordinary" team production also apply to "leadership" teams with responsibility for making organizationwide policy decisions.

Teams will be used to make organizationwide decisions, whenever teams can do so better than individuals and team production problems can be solved. In such cases, there will be standing reward systems for persons holding leadership posts that align their interests with those of the organization. The reward systems will often be composite ones that combine pecuniary and nonpecuniary rewards. The mechanisms used to recruit persons to such teams will take account of both managerial talent and the ease with which such persons can be motivated to "work," rather than "shirk" at their positions in the organizational government.

The initial reward and recruiting systems for leadership posts will normally be chosen by formeteurs, and there will be a tendency for formeteurs to use time-proven templates for governance and for those templates to converge through time. The decisionmaking systems themselves are also likely to be rule based and relatively stable through time, but will be adjusted as relevant technologies and theories change.

\footnotetext{
${ }^{5}$ Witt $(1997,1998)$ makes similar points about entrepreneurs, whom, he notes, need firms as well as good ideas and who often use nonpecuniary means to motivate their team members.
} 
However, there are a number of differences between leadership teams (organizational governments) and ordinary teams within an organization. One obvious distinction is that the "output" of the leadership team is largely the organization itself, rather than a service or product to be sold or an idea to be disseminated to outsiders. Another is that formeteurs often play a more central role in the governing decisions of their organizations than in day-to-day production. Another destinction of particular relevance for the purposes of this paper is that the problems of organizational governance tend to be more similar than the specific problems of team production that organizations confront, and so governing institutions tend to be more similar than other production methods.

\section{A. Why Every Durable Organization Needs and Has a Government}

If circumstances inside and outside the organization were entirely stable, it is possible that a well-adapted reward and recruiting system would simply be left in place to "run" without active monitoring and review by an organizational government. However, circumstances are never completely stable, and no reward or recruiting system works equally well in all circumstances. As a consequence, organizations benefit from being able to adapt to changes in circumstances, which is often necessary if they are to survive in the long run. Clearly, A fishing club that continues fishing at the same pond after all the fish are gone would disappear as its members starve or leave for clubs that actually catch fish. Similarly, a cherry picking firm that continues to focus on the same grove after it is weakened by disease or insects, rather than turn to other groves or other fruit, would disintegrate as members leave to find more fruitful firms with higher wages, whether in kind or cash.

To adapt to changing circumstances, an organization must have routines for revising its objectives, methods of production, reward system, and recruiting system. To do so reliably normally requires a standing group of persons with a standing set of procedures for gathering information, evaluating alternatives, and making policy decisions. That is to say, it normally requires an organizational government.

To the extent that an organization's decisionmaking procedures are stable, an organization may be said to have a constitution. An organizational constitution is the collection of formal and informal standing procedures for making policy decisions. (An organization's constitution can be said to be the rules for making an organization's rules.) Consti- 
tutions in this sense are not usually social contracts, nor are they always written down. Moreover, an organization's constitutions are not usually the product of a grand constitutional convention in which all of an organization's members are represented. Rather, an organization's initial procedures for policymaking are normally adopted by an organization's formeteurs.

Formeteurs normally select their organizational governments from a menu of preexisting constitutional templates that are believed to work well, in the sense that they increase the organization's survival prospects and the risk-adjusted organizational surplus available to organizational leaders. Organizational governments do so by appropriately revising standing routines and objectives to take account of new internal and external circumstances. Only governmental templates that do so reasonably well tend to survive in the long run.

As in other aspects of organizational design, the procedures of governance may also have to be adjusted from time to time as circumstances change. It is this that gives organizational governance an evolutionary character at both the level of a single organization and as a social phenomenon. An organizational constitution is not carved in stone, because there are benefits associated with flexibility in governance.

\section{B. The Informational Advantages of the King and Council Template}

Many of the problems associated with devising an organizational government are similar across organizations, as noted above. The similarities allow the experience of earlier organizations to be used to inform decisions of later ones. The same logic applies to organizational governance. If successful organizations use similar arrangements for making their policy decisions, this will be recognized, and formeteurs will tend to adopt similar institutions for their new organizations. They will do so for many of the same reasons that they tend to use preexisting templates for reward and recruiting systems. Proven templates for governance reduce the risk of failure and the time necessary to establish a new organization.

The next four subsections of this paper argue that the king and council template for governance is one such template. The analysis begins by pointing out the informational advantages of this template and then discusses how the king and council template can be used to solve other medium- and long-term problems: to address succession problems as 
an institution for trading authority inside and outside the organization and as a method for reducing losses from conflict.

\section{Natural Governments for Organizations}

Perhaps the most "natural" form of organizational governance is the one (implicitly) assumed by most economists and also by many political theorists. Formeteurs may simply retain their initial authority to make and revise all major policy decisions after their organizations are up and running. A single individual may initially retain complete control over an organization's policies in cases in which an organization is founded by a single formeteur. In cases in which a small group of formeteurs founds an organization, a ruling committee or council may retain control over the organization's policies.

Such “authoritarian" decisionmaking procedures have many advantages for formeteurs and their organizations. Formeteurs often have a superior understanding of organizational possibilities, which justifies their initial investment of time and attention to assemble a team and devise methods to advance particular goals. Formeteurs know their own goals better than others and are likely to have leadership skills that allow them to form and motivate groups at lower costs than others.

As organizations increase in size, however, informational, resource, and design problems become more complex. For example, an organization's conditional reward structure may require a good deal of monitoring of team member performance. New teams may be added and others eliminated or merged into others. The external circumstances may change in unpredicted ways and require the organization's goals and/or conditional reward system to be revised. Exit options for some team members may rise while others fall.

To assist in gathering information and evaluating alternatives, formeteurs will often find it useful to assemble a team of "advisors," who specialize in monitoring internal and external events that may affect the organization's surplus. Unfortunately for formeteurs, simply assembling a team of advisors does not automatically improve the quality of organizational decisions.

Formeteurs usually confront what Wintrobe (2000) calls the "dictator's dilemma." It is often in the interest of "advisors" simply to tell a dictator what he or she wants and/or expects to hear, especially when the dictator has complete control over organizational 
rewards. In such cases, an in-house council of advisors would not add much to an authoritarian organizational government's stock of information or improve its decisions. Indeed, it may worsen those decisions by making the organization's leadership over confident.

\section{Solving the Dictator's Dilemma}

To address the dictator's informational dilemma requires somewhat more sophisticated institutions for "advice production." To advance informational goals and reduce bias, formeteurs will often use committees of various types, the most important of which will play both direct and indirect roles in the policy decisions of their organizations. The members of those committees will tend to have expertise on matters of organizational interest and represent diverse interests.

To enhance the value of the information passed on to the formeteur(s), the committee may be advised to use majority rule to choose policy recommendations and to make "consensus" forecasts about the consequences of policies. Under majority rule, median voter outcomes tend to emerge, and in the context of an advisory committee, the median member's advice can be thought of as a median estimator. Median estimators tend to be relatively robust and unbiased estimators. Condorcet's jury theorem relies, implicitly, on the estimation properties of median estimators (Congleton 2007).

To motivate the committee, it is often useful to delegate some genuine decisionmaking authority to them. This makes them partly responsible for the result, making it easier to punish mistakes and reward insightful decisions. (A mere advisor can simply provide a balanced list of pros and cons in order to shift responsibility to the formeteur.) Authority is also a good that many people value for its own sake. Even limited authority may increase a person's status or have reputational effects that increase the value of his or her information services to others. The latter may produce opportunities for consulting, and even limited policymaking authority may produce opportunities to profit from the efforts of rent seekers. In addition, delegating some authority to the advisory committee tends to free formeteur time and attention for other tasks, such as long-run planning, forming of new organizations, and liesure. In this manner, a divided form of the king and council template tends to emerge from initially authoritarian regimes. 
Similar, but slightly different, informational advantages can also induce councils of formeteurs to employ "kings" (chief executive officers) and delegate some authority to them. A formeteur council has a variety of informational advantages over a single formeteur. For example, the formeteurs can pool information and average their individual estimates to create an accurate consensus forecast. However, members of the council may also free ride on information, analysis, and decisionmaking calculus. Council members receive only part of the benefits from better management decisions, but all the cost for their own efforts to improve the decision.

Appointing a chief executive officer (CEO) can improve intra-organizational monitoring by reducing free-rider problems associated with monitoring; it can also improve day-to-day policymaking by reducing other informational and analytical free riding and various decision costs. This frees time for formeteurs to focus on other matters.

\section{E. Succession and the King and Council Template}

Overall, the above suggests that informational advantages provide sufficient reasons for "kings" to have "councils" and for "councils" to have "kings." It also suggests that informational advantages can sometimes be realized by shifting authority from the formeteurs to their advisors, managers, or persons initially outside of the organization. There are also noninformational reasons to use the king and council template and for formeteurs to shift part of their initial authority to others. The king and council template includes a large number of parameters that can be adjusted at the margin to address short, medium, and long run governance problems. Many of these affect the distribution or nature of policymaking authority.

For example, the king and council template provides a number of useful methods for solving succession problems. Every durable organization will eventually outlive its formeteurs. Organizations that do not systematically replace their leaders may flounder because of as formeteur competence declines with age, or may disappear as policymaking is disrupted and internal infighting for leadership posts consumes the organization's surplus after the formeteur departs. A systematic method for replacing successive generations of leaders tends to increase an organization's long-run survival prospects, because effective governance contributes to an organization's survival. 
The king and council template provides a number of possible systematic ways for successive generations of organizational leaders to be replaced. Replacements for the unexpected departure of a king may be selected by the council. Similarly, unexpected departures of council members can be selected by the king and/or surviving council members. Such choices tend to be fairly good ones, because surviving council members normally have the long-term interests of the organization in mind and are relatively well informed about the qualities required for good decisionmaking at the council level. Moreover, it is unlikely that both the king and the council will simultaneously disappear in an unexpected manner, although the king or individual members of the council may do so.

To the extent possible, productive forms of competition for seats in the organization's government might also be encouraged. Council seats may, for example, be reserved for persons that have provided extraordinary service to the king or kingdom. Challenging examinations on matters relevant for councilor or royal duties can also be contrived. ${ }^{6}$

In large organizations, king and council templates may be used to delegate authority for specific production activities within the organization. The latter can create a divided, hierarchical, organizational government with many areas of limited specialized authority to make policy decisions. The same hierarchy can be used to assess loyalty and talent for making policy decisions and to induce productive forms of competition among persons at similar levels within the organization for promotion to higher ones.

Such contests can serve as indirect "auctions" for future seats in government that allow the current generation of leaders to extract surplus (rents) from the next one. Such contests, perhaps surprisingly, provide the current generation of officials with a good reason to "care" about their organization's long-term success. The next generation of leaders will "pay" more for leadership posts in successful organizations than in ones that appear doomed to failure.

In cases in which it is not possible to constrain rivals for high office to "play by the rules," other possibilities also exist. For example, some of the positions in government may be deemed inheritable, which tends to reduce unproductive conflict at times of succession. Such rights might also be subject to the veto of other parts of the government.

${ }^{6}$ Unfortunately, it is often difficult to encourage all rivals for high office to play by the rules devised. Such problems can be reduced by imposing severe punishments on those that violate the rules of successional contests. 
For example, the persons holding positions in the council or as king may be able to pass their positions along to their children (hereditary succession), unless vetoed by a supermajority of council members (and/or the king). Such compound systems also reduce conflict, because they reduce the number of potential successors, and also help avoid negative genetic shocks.

\section{F. The King and Council Template and Markets for Authority}

Methods for choosing successors are only one of many continua along which adjustments to the king and council template can be made. Other important institutional continua involve the division of authority between the king and council and among council members.

"Power" (policymaking authority) is often represented as if it were a single lexicographic dimension, in which case, peaceful shifts of authority would be impossible; but policymaking authority is in fact multidimensional and most persons are less attached to power than implied by those who employ lexicographic representations of the demand for authority. As a consequence, shifts of policymaking authority often take place, as authority is traded within the leadership team or between the leadership team and others inside and outside their organization. Such trades are possible, because a stable distribution of policymaking authority creates political property rights that can be bought and sold much like control over ordinary goods and services. ${ }^{7}$

Although a founding formeteur or council of formeteurs usually holds onto most of his or its authority in the early days of an organization, many intermediate divisions of authority are also possible; these can often be used to increase organizational surplus. In many cases, an organization's leadership will find that the benefits from additional resources exceed the losses from reduced control of "their" organizations. Many of these "constitutional bargains" can be implemented using the king and council template.

\footnotetext{
${ }^{7}$ It bears noting that exchanges in ordinary private markets can be thought of as changes in the distribution of authority. When person A trades person B some X for $\mathrm{Y}$, A gives up his authority over $\mathrm{X}$ in exchange for new authority over $\mathrm{Y}$, and $\mathrm{B}$ receives new authority over $\mathrm{X}$ in exchange for giving up authority over Y.
} 


\section{G. Constitutional Gains to Trade}

Table 2 illustrates a pattern of risk and reward that can induce authority-sharing bargains in which new persons are brought into an organization's government or at least into positions where they can systematically influence organizational decisions.

\section{Table 2}

Mutual Gains from Sharing Authority

\section{Organizational Leadership}

\begin{tabular}{|c|c|c|c|c|}
\hline & & $\begin{array}{l}\text { No } \\
\text { Authority }\end{array}$ & $\begin{array}{l}\text { Shared } \\
\text { Authority }\end{array}$ & $\begin{array}{l}\text { Complete } \\
\text { Authority }\end{array}$ \\
\hline & $\begin{array}{l}\text { Complete } \\
\text { Authority }\end{array}$ & 8,10 & - & - \\
\hline $\begin{array}{l}\text { Potential } \\
\text { Team Member }\end{array}$ & $\begin{array}{l}\text { Shared } \\
\text { Authority }\end{array}$ & - & 10,12 & - \\
\hline & $\begin{array}{l}\text { No } \\
\text { Authority }\end{array}$ & - & - & 6,14 \\
\hline
\end{tabular}

The initial state is the one characterized by the upper left-hand cell of table 2 in which a resource of interest to the formeteur(s) is entirely controlled by a non-team member. The organization's leadership is better off if it obtains complete control over that person's (or group's) resources, than if it obtains shared or no control $(14>12>$ 10). The prospective team member is better off with shared control than with complete or no control. Retaining complete control requires sacrificing advantages from team production, while giving up complete control places his or her resources at greater risk than under shared control $(10>8>6)$. In cases like the one illustrated, there are gains to trade, but realizing them may require sharing policymaking authority in at least a narrow range of the organization's activities.

Many such cases involve risks associated with temporary transfers of control over a resource. For example, prospective cherry pickers who are especially adept at climbing trees or own ladders may fear that their talents or ladders will be abused by the organization's leadership. Such temporary members and their ladders may always be assigned to the most dangerous trees. Such persons would be more willing to participate in the annual harvest, if they have some veto authority over the trees to which they are assigned. Their risks (broken legs and ladders) can be reduced by "giving" them limited veto power over the use of their ladders and/or assignments to particular treetops. 
Similarly, a regional government that confronts an external threat from pirates or neighboring navies may benefit from the use of commercial ships in defense of their territory. The owners of commercial ships, however, may be unwilling to allow their ships to be under the command of the regional government. They might fear, for example, that the government would assign their ships to the most dangerous missions, while holding the government's own ships in reserve. Granting the commercial ship owners some authority to veto or at least influence how their ships will be used may make them more willing to allow their ships to be used for regional defense, benefiting both the kingdom and the ship owners.

Entrepreneurs of commercial organizations engage in similar transactions when they sell shares of stock (as in an initial public offering [IPO]) to investors, who provide capital in exchange for claims against future profits and some control (voting rights) over major firm decisions. In this manner, those founding the firm often voluntarily transfer some (but not all) authority to shareholders and/or to a council elected by the new shareholders (board of directors). How much authority is transferred depends partly on risk assessments of capital owners, which determines their demand for control. High demands for authority by potential shareholders tends to increase both the scope of voting rights and how many seats on the board of directors are allocated to members elected by shareholders.

Similarly, the medieval kings of Europe often traded (sold) policymaking authority to parliaments and towns in exchange for new tax revenues. In some cases, new seats in parliament or in ministries were created and directly or indirectly sold to those with an interest in public policy decisions. In others, authority was simply shifted from the king to the council or from the council to the king in exchange for other services or privileges. Many such transactions took place between European kings and parliaments in the period between 1400 and 1900, as parliaments traded new taxes for new policymaking authority (Congleton 2011: Part II).

In none of the above cases are threats of violence necessary for shifts of authority (power) to take place. However, it must be acknowledged that threats of violence can also induce shifts in authority. 


\section{H. The King and Council Template Can Be Used to Reduce Unproductive Conflict}

A related, but somewhat different, case occurs in settings in which two or more parties struggle to control a given resource. Again, there may be constitutional gains to trade, and, again, the king and council template may be adopted or modified as a means of reducing losses from inter- or intra-polity conflict.

Table 3 illustrates a contest in which resources are invested in such a contest. Resources are wasted in this contest, because the joint payoffs fall as conflict intensifies. Conflict in such cases reduces the extent to which the contested resources can be used for productive purposes or consumes resources taken from other more productive activities. The Nash equilibrium is wasteful, because the total output (which can be regarded in objective terms in this case) are lower than they would have been with less intense conflict. As in the previous cases, unrealized potential gains can be realized through improved institutional design.

\section{Table 3: Asymmetric Conflict \\ Stronger Party}

\begin{tabular}{llll} 
Weaker Party & \multicolumn{1}{c}{ Little Aggression } & \multicolumn{2}{c}{ Moderate Aggression Intense } \\
Little Resistance & 6,14 & 3,16 & 0,18 \\
Moderate Resistance & 7,10 & 4,12 & 1,14 \\
Intense Resistance & 8,8 & 5,10 & 2,12
\end{tabular}

One possible solution to external conflict and internal rent-seeking problems is to use a less resource-intensive method of "collective choice." Alternative collective choice mechanisms do not generally eliminate all losses from conflict, but can reduce the cost of conflict by encouraging the use of more "civil" forms of social choice (Congleton 1980). Replacing "uncivil" with "civil" conflict tends to reduce the extent to which resources are consumed by changing the process of conflict, which can be an effective way to reduce losses. The king and council template can be used for this purpose, because it provides a broad range of possible divisions of authority.

Similar gains from sharing authority can also arise when organizations or communities decide to merge their governments to realize economies of scale, diversify risks, or reduce transaction costs. In such cases, sharing policymaking authority allows the inter- 
ests of the merging organizations or communities to be protected against rent extraction by the other, while the additional joint output or reduced risks make governmental officeholders and residents better off. (Only the former is necessary for a voluntary exchange of authority to take place at the level of organizations or governments.)

The king and council template allows policymaking authority to be divided between the king and parliament or among members of parliament (through weighted voting or special veto powers) in a manner that can approximately replicate the payoff ratios of the initial equilibrium, while reducing the extent of the resources consumed by conflict.

\section{The Evolutionary Possibilities of the King and Council Template}

The "market for power" provides an important mechanism through which governments based on a king and council can evolve. Such internal and external markets provide a self-interested explanation for changes in governance procedures. The distribution of policymaking authority and methods through which those in leadership posts are chosen may be adjusted at any time as constitutional gains to trade emerge. Other existential crises, such as those created by threats of violence or natural disasters, can also induce revisions, as can improved knowledge about the performance of alternative institutional design.

The king and council template, in turn, provides a large number of margins on which both constitutional exchange and experiments can take place.

\section{A. Demand Shocks and Random Walks}

Such refinements of organizational governance are often intentional, although they are often induced by changes in circumstances beyond the control of the organization or its leadership. The market for authority implies that external shocks can affect organizational governance and the future policies through differential effects on willingness to pay for authority. For example, changes in the relative willingness to pay may arise through effects on theories used to forecast the effects of current policies and decisionmaking procedures and through changes in the underlying value of an organization's services (Congleton 2007b, 2011).

Such "demand shocks" may occur in a more or less uniformly distributed manner; in which case, policymaking authority would tend to follow a random walk, with the initial 
point determined by the formeteur(s) and their objectives. If the distribution of authority does not affect the magnitude or variance of organizational surplus, a wide variety of organizational governments based on the king and council template would tend to emerge through time and be implemented in an approximately efficient organizational surplusmaximizing manner. There would be proprietorships, partnerships, shareholderdominated firms, and cooperatives, all equally effective in advancing their organization's objectives.

\section{B. Survivorship Pressures}

However, if some objectives are more effectively advanced with some balances of authority and selection processes than others, both the governance menus confronted by formeteurs and the distribution of organizational governments that survive would be affected by external demand and supply shocks.

The typical form of government adopted in such cases would tend be that which was most appropriate for the enterprise. Rather than a random walk, in such cases, the balance of authority would tend to be clustered around the most efficient ones (from the perspective of formeteur interests), because both organizational surplus and survivorship would be affected by the relative effectiveness of organizational constitutions in the areas of interest. Convergence in governance institutions for similar activities would take place because of formeteur interests and survivorship pressures.

\section{Advantages of Somewhat Flexible Institutions for Governance}

In cases in which survivorship pressures exist, amendment processes tend to become an important part of an organization's constitutional design, because they affect the rate at which an organization's government can be revised as circumstances change. A totally rigid design would require the founding of entirely new organizations to deal with new circumstances. A totally flexible form of government (a very easily amended one) would increase risks that changes in governance would undermine decisionmaking procedures, increasing errors and intraorganizational rent seeking. Constitutional bargains may be too difficult or too easy to make.

In such settings, robust templates for organizational governments would include more or less appropriate amendment procedures. Unfortunately, discovering the best 
amendment procedure tends to take much more time than many other aspects of organizational design, because the relative advantages of rapid or slow adjustments in decisionmaking procedures requires exposure to a broad range of operating environments and shocks. Indeed, the best amendment procedures are likely to be conditional on the types and distributions of shocks confronted and so may need to be adjusted when major shifts in the stochastic operating environment occur.

The fact that organizations can be too rigid to survive changes in operating environment suggests that the evolution of organizational governments favors somewhat adaptable structures, such as the king and council template, that can be adjusted at various margins. The fact that flexibility increases uncertainty and unproductive rent seeking suggests that evolution also favors somewhat restrictive amendment procedures that limit the types of constitutional bargains that can take place. The balance between flexibility and predictability largely determines the optimal difficulty of amending an organization's standing routines of governance. In the long run, the existing menu of amendment procedures would reflect past formeteur design experiments and organizational survivorship, as in other aspects of organizational design.

\section{Difficulty of Observing the Evolution of Organizational Governance}

Shifts of authority have two kinds of effects. Shifts of authority may affect institutionally induced interests, which often have relatively small effects on policy. The effects of such internal shifts in authority are often invisible to outsiders, because the effects of shifts in authority are often small and subtle. This is partly because maximizing the organizational surplus is a common (institutionally induced) objective for an organization's senior government officials. As a consequence, general policy decisions tend not to change very much as shifts of authority occur, except insofar as noninstitutional interests differ. For example, estimates of the relationships between policies and organizational surplus may differ somewhat, or there may be differences in risk aversion among office holders.

Shifts of authority may also affect the non-institutional interests that affect policy decisions though representational effects. The effects of shifts in authority between the king and the council are most evident when the king and the council represent different intraor extra-organizational interests. In such cases, some policies become more likely to be adopted and others less so. For example, within a commercial enterprise, greater repre- 
sentation of shareholder interests on boards of directors may lead to higher dividends or lower salaries for organizational leaders. Greater representation of engineers may lead to higher capital investments, greater representation of marketing experts may induce larger investments in ad campaigns and product styling, and greater representation of labor interests may produce shorter workdays or more holidays. Similarly, in natural or regional governments, changes in the balance of authority between the king and parliament may favor particular regions or interest groups. The king may favor colonial enterprises, and the parliament may favor infrastructure investments. It is largely because of such policy effects that authority is valued.

Such representation effects can also be induced by changing the selection methods for leadership posts. For example, rules that require firms to include representatives from major shareholders or labor unions on their boards of directors will tend to change the debates within the board and may affect policy decisions on the margin, insofar as the new members produce new majority coalitions and/or their arguments affect board member expectations about the effects of alternative organizational policies. Similarly, different electoral rules in political systems tend to change the relative importance of subsets of voters, for example, as the interests of male voters become relatively less important and those of women more so when women's suffrage is introduced.

\section{On the Relevance of the Analysis for Territorial Governance}

Congleton $(2001,2007 b, 2011)$ suggests that the above models of organizational governance can be used to explain many of the common features of the organizations that ruled particular geographic territories (the other meaning of the word "government" in English) and also to explain why several such governments gradually became liberal democracies in the eighteenth and nineteenth centuries. The evolutionary hypotheses developed in this paper can also be checked using the governments of Western Europe as organizational illustrations and data.

Much of European history is consistent with the above analysis. The persons working for European territorial governments were normally carefully selected and motivated to advance organizational objectives using complex systems of reward, which were partly based on salary and prospects for promotion, but also on loyalty and reinforced by severe punishments for malfeasance. There were normally appeals to duties of various sorts 
(family, god, and country), as well as salary. Contests for many high offices often induced the production of substantial services to the current generation of government leaders.

"Rents" (organizational surplus) were largely concentrated in the accounts of governmental leaders, rather than spread uniformly throughout their ruling organizations. This is evident in the homes of the leaders of most governments before 1800, who built monumental palaces, churches, and castles that continue to attract tourists worldwide today. (The homes of "mere" foot soldiers and clerks rarely attract tourist interest.) In cases in which new polities were founded by a single military commander, the "king" normally had dominant policymaking authority. In governments founded as defense alliances, councils of various kinds often had dominant authority over public policy, as in the Dutch Republic, Switzerland, and United States. Free towns founded as commercial centers were often ruled by balanced king-and-council systems with a mayor and a town council.

For much of European history, governance was based on the king and council template and constitutional gains to trade occasionally arose among the branches of government. Most kings had both royal councils and parliaments. Most republics had governors or mayors as well as representative assemblies. Policymaking authority shifted repeatedly from the kings to parliaments and from parliaments to kings, often without obvious threats of violence or revolution, and often without obvious trends. Most individual shifts were relatively minor ones, but a wide variety of distributions of authority was observed over the course of the Middle Ages and early modern period.

During the eighteenth and nineteenth centuries, a new trend in both demand and supply shocks emerged. These technological and ideological shocks tended to favor councils (parliaments) over their kings in constitutional negotiations. Supply shocks also occurred that made kings more willing to trade authority for additional parliamentary subsidies (new tax revenues), because the cost of governance and warfare had increased. Parliaments, thus, gradually traded new tax revenues directly or indirectly for greater authority over policy. The same shocks also helped induce changes in the manner in which government leaders were chosen, although through a somewhat different mechanism. Elections became increasingly broadly based and competitive. Seats were shifted to new regions of the country where industrial organizations emerged. 
Over the course of a century of such constitutional bargaining, "new" forms of government emerged. The templates of these new governments were often grounded in governance architectures that were centuries old (multi-cameral parliaments, kings, and cabinets), but the leaders of the new governments increasingly held their positions as a consequence of elections based on adult suffrage and parliaments became the main locus of policymaking authority. That the new distribution of authority reflected bargaining, rather than revolution, was also clearly evident. Many European kings and queens retained their offices as "heads of state," albeit with very limited policymaking authority, and most continued to live opulent lives.

Gains from constitutional exchange within the king and council template had allowed a new form of government to emerge (parliamentary democracy), without the need for great revolutions or revolutionary shifts in the basic template for governance. ${ }^{8}$

\section{Conclusions: On the Form, Basis, Limits, and Evolution of Organizational Governments}

This paper has developed a general framework for analyzing the evolution of organizational governance. It makes several general predictions about the kinds of institutions and institutional adjustments that can be observed in practice. To survive, all organizations must solve a variety of organizational problems. They have to recruit and motivate teams and advance objectives in a manner that is "self-financing." They have to be able to adjust both their methods and objectives as circumstances.

The common interests and problems of formeteurs imply that the templates for organizational governance share a number of properties, a subset of which have been identified and analyzed in this paper. Every durable organization will have a body of internal procedures for making policy decisions that serve as its charter or constitution for governance. The standing rules normally specify the officeholders who participate in major decisions and the manner in which those officials interact to make decisions, as with voting and appointment rules. The latter may include specific architectures for policymaking that group and/or assign tasks to subsets of officeholders. The standing procedures of long-lived organizations also include rules governing the

\footnotetext{
${ }^{8}$ Congleton (2011) provides much more theoretical and historical detail than can be provided in this section of the paper. For those interested in more complete analyses and histories of the evolution of territorial governance in Europe, North America, and Japan, see chapters 5-18 of that volume.
} 
selection and succession of officeholders, and standing procedures for modifying the organization's charter.

The governmental templates that attract formeteur interests will tend to collect and use information relatively efficiently and to produce decisions that increase the viability of their organization, while advancing their organizational interests. Improvements from the point of formeteurs tends to concentrate organizational surplus in the hands of governmental leaders, because this is often the goal of formeteurs.

\section{A. Organizational Templates Reflect Formeteur Interests}

The founding charters (constitutions) of organizations always favor formeteur interests, because formeteurs draft their organization's founding documents. This founding role also implies that evolution favors organizational templates that concentrate organizational surplus in the hands of formeteurs and their successors, because only templates that attract sufficient interest from past formeteurs remain on the organizational menu.

That the evolution of organizational structures tends to favor formeteurs, rather than employees or shareholders, provides an explanation for the reward structures of many large contemporary economic enterprises in which senior executives (the enterprises' government) realize very high salaries relative to other team members. Similar reward structures have often been associated with territorial governments and religious organizations. Even in contemporary democracies, the expression "lives like a king" has a clear meaning.

The interests of formeteurs and the requirements of team production also explain why most organizations use mixed forms of conditional incentives to solve team production problems and why both internal incentive systems and organizational policy tend to be somewhat flexible at the margin, although core policies tend to be fundamentally stable and similar among organizations. An organization's system of governance and its reward system tend to be stable, because organizations tend to make better decisions and are better able to retain and train their teams when they have "institutionalized" their reward and governance systems.

Formeteur interests imply that one man or one woman is unlikely to govern alone, even when a single person founds the organization. In all but the smallest of organizations, the "king and council template" for governance is likely to be used for choosing and refining policies, because it addresses a variety of short-, medium-, and long-term governance problems. King and council-based governments address short-term informational problems, can be "finely tuned" to take advantage of new circumstances, and can be used to realize constitutional gains to trade, 
without changing the fundamental architecture of the organization's government. They also provides several natural solutions to problems of succession and power sharing.

\section{B. Rational Institutional Conservatism}

Although the existence of an organizational government potentially allows organizations to change policies at every instant and the existence of amendment procedures potentially allows organizations to reinvent their procedures for governance every day, durable organizations will not do so. There are good reasons for organizational governments to prefer stability to innovation in both the routines of ordinary team production and governance. Such rational institutional conservatism is supported by the risk aversion of government officeholders and team members, and various economic advantages associated with being "conventional." As a consequence, both succession and amendment procedures tend to encourage governance stability and continuity.

As in other aspects of organizational design, formeteurs choose their organization's formal amendment procedures with their own interests in mind.

Most will acknowledge their limits as institutional designers and so will include provisions for revising their standing procedures of governance as problems and opportunities are recognized. Insofar as small reforms are easier to assess and implement than large reforms, the amendment procedures adopted will tend to favor piece-meal reforms that address particular problems, rather than "reinventing" the entire organization. Such modest reforms preserve advantages associated with stable procedures and help to avoid unforeseen costs generated by experimental failures. They also increase the predictability of reward and recruiting systems, which tends to reduce the cost of those systems and increase organizational surpluses.

Nonetheless, gains from experimentation and constitutional exchange do emerge from time to time, and the amendment procedures that allow such gains to be realized tend to produce more robust organizations in the long run. Shifts in the long-term interests of organizational leaders and technologies of production have to be accounted for, and adjustments to a variety of standing procedures of governance may be required to take advantage of new more or less permanent conditions.

\section{The King and Council Template Facilitates Both Evolution and the Analysis of Organizational Governance}

For the purposes of developing models of organizational governance, the widespread use of a single flexible template for governance is a fortunate consequence, because it also allows a broad range of organizations to be analyzed with a single model or conceptual framework. The theory of organizations proposed above implies that the king and council framework and most 
short- and long-term reforms of it are consequences of decisions made by organizational leaders. This allows the effects of interests and stochastic shocks to be analyzed in the short, medium, and long run, using models grounded in methodological individualism, as sketched out in the last few sections of this paper.

The king and council model also allows a large number of government types, from dictatorships to aristocracies to democracies, to be represented within a single conceptual framework. The many continua of potential reforms imply that both extreme and intermediate forms of governance can emerge incrementally from the others through a series of reforms. This allows evolutionary research strategies to be used to explain the distribution of governance forms observed in particular types of organizations and in particular industries and to predict those that are likely to emerge as circumstances change.

The same flexibility that makes the king and council template a practical, robust template for organizational governance also allows the king and council model to be used as the basis for general analyses of organizational governance, reform, and evolution. This paper has begun that analysis, although much more remains to be done. 


\section{References}

Baden-Fuller, C. and S. G. Winter (2005) "Replicating Organizational Knowledge: Principles or Templates?" Papers on Economics and Evolution, \# 0515, Max Planck Institute of Economics, Jena, Germany.

Buchanan, J. M. (1975) "A Contractarian Paradigm for Applying Economic Theory," American Economic Review 65: 225-30.

Congleton, R. D. (2011) Perfecting Parliament: Constitutional Reform, Liberalism, and the Rise of Western Democracy. Cambridge: Cambridge University Press.

Congleton, R. D. (2007a) "Informational Limits to Democratic Public Policy: The Jury Theorem, Yardstick Competition, and Ignorance," Public Choice 132 (2007): 333-52.

Congleton, R. D. (2007b) "From Royal to Parliamentary Rule without Revolution, the Economics of Constitutional Exchange within Divided Governments," European Journal of Political Economy 23: 261-84.

Congleton, R. D. (2001) "On the Durability of King and Council: The Continuum between Dictatorship and Democracy," Constitutional Political Economy 12: 193-215.

Congleton, R. D. (1991) “The Economic Role of a Work Ethic," Journal of Economic Behavior and Organization 15: 365-85.

Congleton, R. D. (1989) "Efficient Status Seeking, Externalities and the Evolution of Status Games," Journal of Economic Behavior and Organization 11: 175-90.

Congleton, R. D. (1984) “Committees and Rent-Seeking Effort," Journal of Public Economics 25: 197-209.

Congleton, R. D. (1980) "Competitive Process, Competitive Waste, and Institutions." in J. M. Buchanan, R. D. Tollison, and G. Tullock, (eds.) Towards a Theory of the Rent-Seeking Society. Texas A \& M Press: 153-79. Reprinted in R. D. Congleton, A. L. Hillman, and K. A. Konrad (eds.) 40 Years of Research on Rent Seeking. Heidelberg: Springer-Verlag (2008): 69_ 96.

Frey, B. S. and R. Jegen (2001) "Motivation Crowding Theory," Journal of Economic Surveys 15: 589-611.

Hayek, F. A. (1948) Individualism and Economic Order. Chicago: University of Chicago Press.

Kirzner, I. M. (1978) Competition and Entrepreneurship. Chicago: University of Chicago Press.

Knight, F. H (1921) Risk, Uncertainty, and Profit. New York: Houghton Mifflin Co.

Nelson, R. R. and S. G. Winter (1982) An Evolutionary Theory of Economic Change. Cambridge, Mass.: Harvard University Press.

Olson, M. (1965) The Logic of Collective Action. Cambridge, Mass.: Harvard University Press.

Schumpeter, J. A. (1934) The Theory of Economic Development: An Inquiry into Profits, Capital, Credit, Interest, and the Business Cycle. Cambridge, Mass.: Harvard University Press.

Stigler, G. J. (1958) "Economies of Scale," Journal of Law and Economics 1: 54 -71.

Vanberg, V. and J. M. Buchanan (1989) "Interests and Theories in Constitutional Choice," Journal of Theoretical Politics 1: 49-63.

Vanberg, V. and R. D. Congleton (1992) "Morality and Exit," American Political Science Review 86: 418-31. 
Williamson, O. (1967) "Hierarchical Control and Optimal Firm Size," Journal of Political Economy 75: 123-38.

Williamson, O. (1996) The Mechanisms of Governance. Oxford: Oxford University Press.

Williamson, O. (2002) "The Theory of the Firm as Governance Structure: From Choice to Contract," Journal of Economic Perspectives 16: 171-95.

Wintrobe, R (2000) The Political Economy of Dictatorship. Cambridge: Cambridge University Press.

Witt, U. (1998) "Imagination and Leadership - The Neglected Dimension of an Evolutionary Theory of the Firm," Journal of Economic Behavior and Organization 35: 161-77.

Witt, U. (1999) "Do Entrepreneurs Need Firms? A Contribution to a Missing Chapter in Austrian Economics," Review of Austrian Economics 11: 99-109.

Witt, U. (2006) The Evolving Economy: Essays on the Evolutionary Approach to Economics. Cheltenham: Edward Elgar.

Wohlgemuth, M. (2002) “Evolutionary Approaches to Politics,” Kyklos 55: 223-46. 